\title{
DNA methylation status of REIC/Dkk-3 gene in human malignancies
}

\author{
Tatsuro Hayashi $\cdot$ Hiroaki Asano $\cdot$ Shinichi Toyooka $\cdot$ Kazunori Tsukuda \\ Junichi Soh · Tadahiko Shien · Naruto Taira · Yuho Maki • Norimitsu Tanaka • \\ Hiroyoshi Doihara $\cdot$ Yasutomo Nasu $\cdot$ Nam-ho Huh $\cdot$ Shinichiro Miyoshi
}

Received: 17 August 2011 / Accepted: 12 January 2012 / Published online: 25 January 2012

(C) The Author(s) 2012. This article is published with open access at Springerlink.com

\begin{abstract}
Purpose The REIC (reduced expression in immortalized cells)/Dkk-3 is down-regulated in various cancers and considered to be a tumor suppressor gene. REIC/Dkk-3 mRNA has two isoforms (type-a,b). REIC type-a mRNA has shown to be a major transcript in various cancer cells, and its promoter activity was much stronger than that of type-b. In this study, we examined the methylation status of REIC/ $D k k-3$ type-a in a broad range of human malignancies.

Methods We examined REIC/Dkk-3 type-a methylation in breast cancers, non-small-cell lung cancers, gastric cancers, colorectal cancers, and malignant pleural mesotheliomas using a quantitative combined bisulfite restriction analysis assay and bisulfate sequencing. REIC/Dkk-3 type-a and type-b expression was examined using reverse transcriptional PCR. The relationships between the methylation and clinicopathological factors were analyzed.

Results The rate of REIC/Dkk-3 type-a methylation ranged from 26.2 to $50.0 \%$ in the various primary tumors that were examined. REIC/Dkk-3 type-a methylation in

T. Hayashi $\cdot$ H. Asano $\cdot$ S. Toyooka $(\bowtie) \cdot$ K. Tsukuda $\cdot$ J. Soh $\cdot$ T. Shien $\cdot$ N. Taira $\cdot$ Y. Maki $\cdot$ N. Tanaka $\cdot$ H. Doihara $\cdot$ S. Miyoshi Department of Cancer and Thoracic Surgery, Graduate School of Medicine, Dentistry and Pharmaceutical

Sciences, Okayama University, 2-5-1 Shikata-cho,

Okayama 700-8558, Japan

e-mail: toyooka@md.okayama-u.ac.jp

Y. Nasu

Department of Urology, Graduate School of Medicine,

Dentistry and Pharmaceutical Sciences, Okayama University,

Okayama, Japan

N. Huh

Department of Cell Biology, Graduate School of Medicine,

Dentistry and Pharmaceutical Sciences,

Okayama University, Okayama, Japan
\end{abstract}

breast cancer cells was significantly heavier than that in the other cell lines that we tested. REIC/Dkk-3 type-a methylation was inversely correlated with $R E I C / D k k-3$ type-a expression. There was a correlation between $R E I C / D k k-3$ type-a and type-b mRNA expression. REIC/Dkk-3 type-a expression was restored in MDA-MB-231 cells using 5 -aza-2'-deoxycytidine treatment. We found that estrogen receptor-positive breast cancers were significantly more common among the methylated group than among the nonmethylated group.

Conclusions REIC/Dkk-3 type-a methylation was frequently detected in a broad range of cancers and appeared to play a key role in silencing REIC/Dkk-3 type-a expression in these malignancies.

Keywords DNA methylation $\cdot R E I C / D k k-3$.

Breast cancer $\cdot$ Lung cancer $\cdot$ Mesothelioma

\section{Introduction}

Accumulating evidence suggests that tumor progression is governed not only by genetic changes intrinsic to cancer cells but also by epigenetic changes. In cancer epigenetics, aberrant $\mathrm{CpG}$ methylation in the promoter region is a key mechanism for gene inactivation, resulting in tumorigenesis in human malignancies (Toyooka and Shimizu 2004).

The REIC (reduced expression in immortalized cells)/ Dkk-3(Dickkopf-3) cDNA, which was expressed in human normal cells and was down-regulated in human immortalized cells and human tumor-derived cells, was identified using a representative difference analysis system (Tsuji et al. 2000). The amino acid sequence revealed that the $R E I C$ gene product was human $D k k-3$, one of the Dkk family members. The Dkk family of secreted proteins consists 
of four members, which share two conserved cysteine-rich domains (Glinka et al. 1998; Krupnik et al. 1999). Dkk-1, the best-characterized member of the Dkk family, functions as a Wnt antagonist or agonist by binding to and inhibiting or activating the Wnt coreceptor LRP6 (Bafico et al. 2001). Unlike Dkk-1, Dkk-2, and Dkk-4, however, REIC/Dkk-3 was recently shown to inhibit TCF-4 receptor activity in lung cancer cells (Yue et al. 2008). TCF-4 activates c-Myc and cyclin D1 through the Wnt/beta-catenin pathway and promotes tumor invasion and metastasis. Because REIC/ $D k k-3$ is down-regulated in a variety of malignancies and the overexpression of $R E I C / D k k-3$ suppresses cell growth, $R E I C / D k k-3$ has been proposed to act as a tumor suppressor (Tsuji et al. 2001; Kurose et al. 2004). Hypermethylation and the down-regulation of REIC/Dkk-3 were observed in a variety of malignancies including non-small-cell lung cancers (NSCLCs) (Kobayashi et al. 2002; Licchesi et al. 2008), gastrointestinal cancers (Maehata et al. 2008), renal clear cell carcinoma (Kurose et al. 2004), acute lymphoblastic leukemia (Roman-Gomez et al. 2004) and osteosarcomas (Hoang et al. 2004). We previously showed the therapeutic effect of REIC/Dkk-3 in prostate cancers (Abarzua et al. 2005; Edamura et al. 2007) and malignant pleural mesothelioma (MPM) (Kashiwakura et al. 2008). In addition, tumor suppression by REIC/Dkk-3 has also been confirmed in other malignant tumors (Hsieh et al. 2004; Hoang et al. 2004).

REIC/Dkk-3 mRNA has two isoforms (type-a,b; GenBank accession AB057804). Many papers have described the methylation status in the promoter of REIC/Dkk-3 type-b (Licchesi et al. 2008; Maehata et al. 2008; Veeck et al. 2009). However, the promoter of REIC/Dkk-3 type-a also seems to be important, since Kobayashi et al. (2002) (the group that first identified the REIC/Dkk-3 in immortalized cells) have demonstrated that the promoter activity of $R E I C / D k k$-3 type-a (major promoter) had an approximately 26-fold stronger effect than that of REIC/Dkk-3 type-b (minor promoter) in a luciferase assay, and the major transcript was $R E I C / D k k-3$ type-a in various cancer cells they tested. They suggested that hypermethylation of the major promoter (type-a) was a major mechanism for the downregulation of REIC expression. They also suggested that the methylation of the minor promoter (type-b) was accompanied with that of major promoter (type-a) in most cases except four lung cancer cells that they tested. Regardless, those four lung cancer cells had type-b hypermethylation, REIC/Dkk-3 type-b expression was detected in those four lung cancer cells. So they discussed the possibility that minor promoter (type-b) was utilized for the expression in a tissue-specific manner, as seen in dual promoter of APC gene.

In this study, we examined the DNA methylation of $R E I C / D k k-3$ type-a in various kinds of cancers by quantita- tive combined bisulfite restriction analysis (qCOBRA) and investigated the correlation between the REIC/Dkk-3 type-a methylation and REIC/Dkk-3 type-a expression. The qCOBRA assay can provide more reliable results because the conventional methylation-sensitive restriction enzyme assay that Kobayashi et al. (2002) performed was recently known to be prone to false-positive results due to spurious incomplete digestion (Xiong and Laird 1997). We also analyzed the correlation between REIC/Dkk-3 type-a and type$\mathrm{b}$ expression in various cancer cell lines. Furthermore, we examined the correlation between REIC/Dkk-3 type-a methylation and the clinicopathological features of primary tumors.

\section{Materials and methods}

Clinical samples and cell culture

Surgically resected specimens of 37 primary breast cancers, 42 primary NSCLCs, 21 primary gastric cancers, 20 primary colon cancers, and 7 MPMs were obtained from Okayama University Hospital (Okayama, Japan), 6 MPMs were obtained from Okayama Rousai Hospital (Okayama, Japan), 5 MPMs were obtained from National Sanyo Hospital (Yamaguchi, Japan), and 27 MPMs were obtained from Karmanos Cancer Center (MI). Ten corresponding non-malignant breast tissues and 10 non-malignant lung tissues were also examined. All tissues were frozen with the liquid nitrogen immediately after surgery and were stored at $-80^{\circ} \mathrm{C}$ until extraction of DNA. Institutional Review Board permission and informed consent were obtained for all cases.

Seven breast cancer cell lines (HCC70, HCC1599, HCC1806, MDA-MB-231, MDA-MB-361, MCF7, and ZR75-1), 11 lung cancer cell lines (NCI-H23, NCI-H44, NCI-H125, NCI-H157, NCI-H1299, NCI-H1819, NCIH1963, NCI-H1975, NCI-H2009, NCI-H358, and A549), 4 MPM cell lines (NCI-H2052, NCI-H2373, NCI-H2452, and NCI-H290), and 6 prostate cancer cell lines (PC3, LNCap-FGC, Du145, Caki-1, Caki-2, and KPK) were examined in this study. MCF7, ZR-75-1, MDA-MB-231, and MDA-MB-361 were obtained from Cell Resource Center for Biomedical Research Institute of Development Aging and Cancer Tohoku University (Miyagi, Japan). Seven cell lines (HCC70, HCC1599, HCC1806, H2052, $\mathrm{H} 2373$, H290, and H2452) were kind gifts from Adi F. Gazdar (Department of Pathology, University of Texas Southwestern Medical Center, Dallas, TX). Six cell lines (PC3, LNCap-FGC, Du145, Caki-1, Caki-2, and KPK) were kind gifts from the department of urology (Okayama University, Okayama, Japan). The other cell lines were obtained from American Type Culture Collection (Manassas, VA). The cells 
were maintained in RPMI-1640 medium (Sigma Chemical Co., Saint Louis, MO) supplemented with 10\% FBS and were incubated in $5 \% \mathrm{CO}_{2}$.

DNA extraction and DNA methylation modification

Genomic DNA was extracted from the surgically resected frozen samples and cultured cells by digestion with SDS/ proteinase $\mathrm{K}$ followed by phenol/chloroform (1:1) extraction and ethanol precipitation. Two micrograms of each DNA was treated with EZ DNA Methylation Kit (ZYMO RESEARCH, Orange, CA), following the manufacturer's instructions, and was stored at $-20^{\circ} \mathrm{C}$ until use.

\section{Quantitative COBRA assay}

Nested PCR was carried out using bisulfite-treated DNA followed by the restriction enzyme digestion. First-round touchdown PCR was performed under the following conditions: $95^{\circ} \mathrm{C}$ for $12 \mathrm{~min}, 40$ cycles of $94^{\circ} \mathrm{C}$ for $45 \mathrm{~s}$, annealing temperature between 58 and $56^{\circ} \mathrm{C}$ for $1 \mathrm{~min}, 72^{\circ} \mathrm{C}$ for $3 \mathrm{~min}$, followed by final extension step at $72^{\circ} \mathrm{C}$ for $7 \mathrm{~min}$ in a $25-\mu \mathrm{l}$ reaction mixture containing $67 \mathrm{mM}$ Tris- $\mathrm{HCl}(\mathrm{pH} 8.8)$, $16.6 \mathrm{mM}\left(\mathrm{NH}_{4}\right)_{2} \mathrm{SO}_{4}, 6.7 \mathrm{~mm} \mathrm{MgCl} 2,10 \mathrm{mM} \beta$-mercaptoethanol, $1.25 \mathrm{mM}$ of each deoxynucleotide triphosphate (dNTP) mixture, $0.5 \mu \mathrm{M}$ of each primer, 0.5 unit of HotStar Taq DNA Polymerase (Qiagen, Valencia, CA), and $100 \mathrm{ng}$ of bisulfite-treated DNA. Second-round touchdown PCR was performed using $0.4 \mu \mathrm{l}$ of the first-round PCR products as a template under same condition, but 47 cycles. Universal methylated DNA and universal unmethylated DNA were used for positive control and negative control, respectively. The location of the $\mathrm{CpG}$ dinucleotides in the exon1 and in the $5^{\prime}$-flanking region of REIC/Dkk-3 is shown in Fig. 1. Primers were designed using Primer Express software ver.1.0 in the promoter region of REIC/Dkk-3 type-a. Primers for the first-round PCR were REIC-COBRA-F1 5'-T GGGTTGTTGTAAGTTTGAAGGT- $3^{\prime}$ and REIC-COBRAR1 5'-CTCACCCACCCCRACTAAAC- ${ }^{\prime}$. Primers for the second-round PCR were as follows: REIC-COBRA-F2 5'-T GAAGGTTAGATAAGAYGGGTTTAGG- $3^{\prime}$ and REICCOBRA-R2 5'-ACCCACCCCRACTAAACCRAAT- ${ }^{\prime}$. These primers were designed to ensure amplification of both methylated and unmethylated forms. Two microliters of second PCR products were digested with 3 units of BstUI (whose restriction site is CGCG) for the restriction fragment length polymorphism analysis. The amplicon of second PCR was named RRCOBRA (Region for REICCOBRA), and the 5 restriction sites of BstUI are shown in Fig. 1. The digested PCR products were visualized on $3 \%$ agarose gels stained with ethidium bromide. The percentages of digested band were analyzed by NIH ImageJ $1.37 \mathrm{~V}$ software (http://rsb.info.nih.gov/ij) as described previously
(Xiong and Laird 1997). We performed linear regression analysis of qCOBRA with nested PCR using serial dilution to examine whether qCOBRA with nested PCR really reflected \% methylation. We diluted unmethylated DNA amplicon with methylated amplicon to make serial dilution (\% methylated DNA; 0, 10, 20, 30, 50, 70, 80, 90, 100\%) and performed qCOBRA, as described above.

Bisulfited DNA sequencing analysis

RRCOBRA was cloned into pCR2.1-TOPO Vector using TOPO TA cloning kit (Invitrogen Life Technologies, Carlsbad, CA) following manufacturer's instructions. To determine the methylation status in the promoter lesion of REIC/ $D k k-3$ gene, five breast cancer cell lines (MCF-7, MDAMB-231, ZR75-1, HCC1806, and HCC1599) and a lung cancer cell line (H1299) were examined. Seven individual clones from each cell line were sequenced using the dGTP BigDye terminator v3.1 Cycle Sequencing Kit with the ABI PRISM 3100 Genetic Analyzer (Applied Biosystems, Foster City, CA).

RNA extraction and reverse transcriptional (RT)-PCR

Total RNA was extracted from cultured cells using RNeasy Mini Kit (Qiagen, Valencia, CA) following the manufacturer's instruction. Oligo(dT)-primed cDNA was synthesized using Super-Script II (Qiagen, Valencia, CA) with DNase treatment. RT-PCR was carried out in $20 \mu \mathrm{l}$ of reaction mixture with $1 \mathrm{xPCR}$ buffer, $200 \mu \mathrm{M}$ of dNTP, $0.3 \mu \mathrm{M}$ of each primer, 0.5 units of HotStarTag DNA Polymerase, and $100 \mathrm{ng}$ of cDNA. A touchdown PCR was performed for REIC/Dkk-3 type-a and type-b under the following conditions: $95^{\circ} \mathrm{C}$ for $12 \mathrm{~min}, 35$ cycles of $94^{\circ} \mathrm{C}$ for $30 \mathrm{~s}$, annealing temperature between 62 and $58^{\circ} \mathrm{C}$ for $1 \mathrm{~min}$, $72^{\circ} \mathrm{C}$ for $3 \mathrm{~min}$, followed by final extension step at $72^{\circ} \mathrm{C}$ for $7 \mathrm{~min}$. As an internal control, RT-PCR for $G A P D H$ was carried out under the following conditions: $95^{\circ} \mathrm{C}$ for $12 \mathrm{~min}, 35$ cycles of $94^{\circ} \mathrm{C}$ for $45 \mathrm{~s}, 55^{\circ} \mathrm{C}$ for $90 \mathrm{~s}, 72^{\circ} \mathrm{C}$ for $90 \mathrm{~s}$, followed by final extension step at $72^{\circ} \mathrm{C}$ for $7 \mathrm{~min}$. The primers for $R E I C / D k k-3$ type-a expression were REIC (a)-F 5'-GGGAGCGAGCAGATCCAGT-3' (exon1a) and REIC(a)-R 5'-TTTGTCCAGTCTGGTTGTTGGT-3' (exon3). The primers for REIC/Dkk-3 type-b expression were REIC(b)-F 5'-TGGGAGCTATTAGCGTAGAGGA T-3' (exon $1 \mathrm{~b})$ and $R E I C(\mathrm{~b})-\mathrm{R} \quad 5^{\prime}$-CATTGTGATAGCTGG GAGGTAAG-3' (exon3). The PCR products were visualized on $2 \%$ agarose gels stained with ethidium bromide. The bands were analyzed using NIH ImageJ $1.37 \mathrm{~V}$ software. The expression ratio in each cell line was defined as the ratio of particular sample when compared to those of H1299. To confirm the responsibility of DNA methylation for $R E I C / D k k-3$ silencing, we treated heavily methylated 

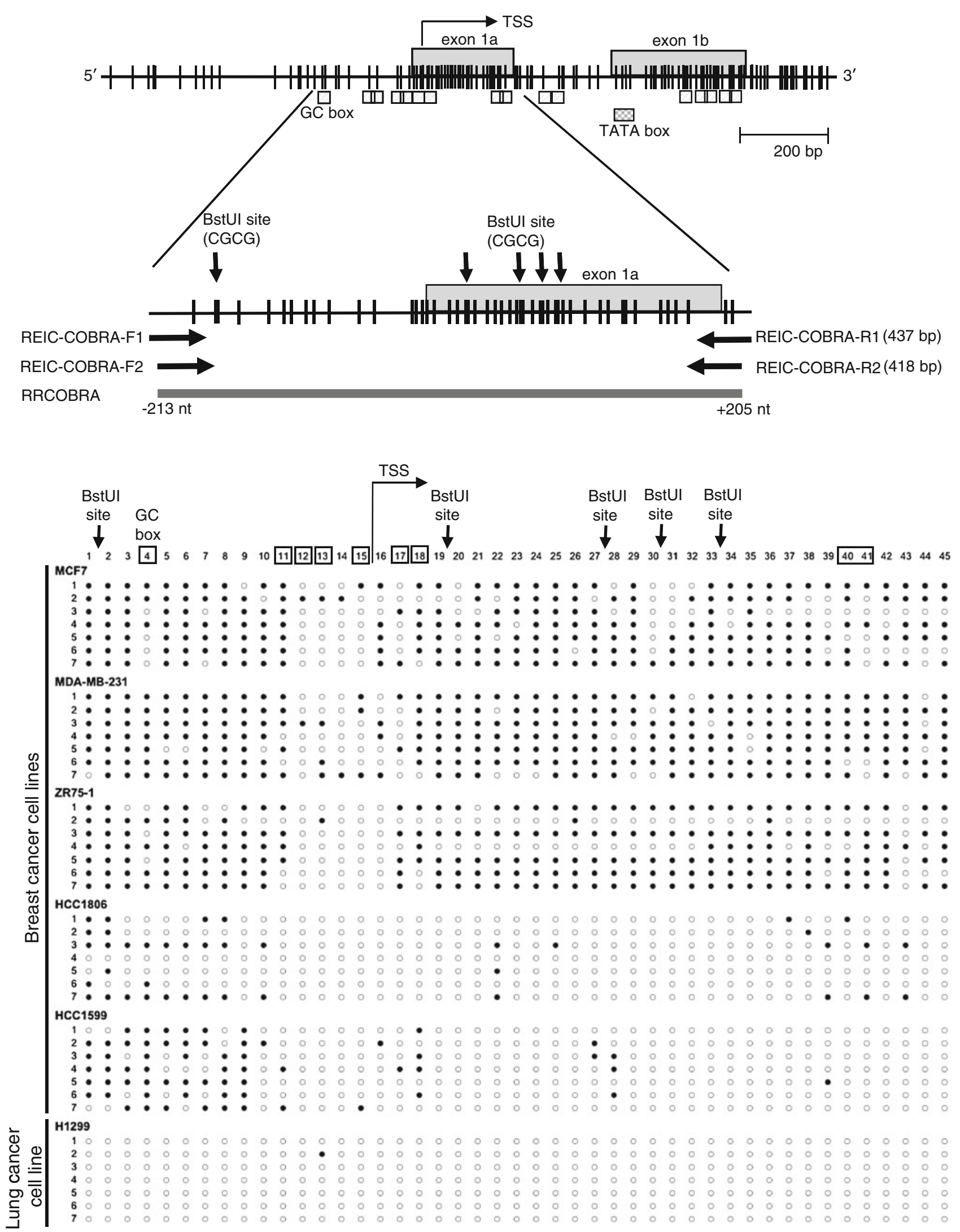
Fig. 1 Map of the $5^{\prime}$-flanking region of REIC/Dkk-3 and the bisulfite genomic DNA sequence. Upper figure demonstrates the promoter region of REIC/Dkk-3. Gray bars indicate exons, and the bent arrow indicates the transcription start site (TSS) $(+1)$. Thin vertical lines on the horizontal line indicate the sites of $\mathrm{CpG}$ dinucleotides. Arrow heads indicate the restriction sites of BstUI. COBRA primer sets are indicated by pairs of bold arrows. Dark gray bar under the COBRA primer sets indicates RRCOBRA. Methylation status of individual subcloned DNA fragments of each cell line is shown below. Each circle represents a CpG dinucleotide in $5^{\prime}$-flanking region of REIC/Dkk-3 (for -213 to $+205 \mathrm{nt}$ ). The numbers at the top indicate the $\mathrm{CpG}$ dinucleotide in the RRCOBRA (from $5^{\prime}$ to $3^{\prime}$ ). These numbers correspond to those depicted in upper figures. Open circle represents non-methylated $\mathrm{CpG}$ dinucleotide. Black circle represents methylated $\mathrm{CpG}$ dinucleotide

cell lines (MDA-MB-231) with 5-aza-2'-deoxycytidine (5-Aza-CdR) at the concentration of 5 and $8 \mu \mathrm{M}$ for 6 days with medium changes on days 1,3 , and 5 . Treated and untreated cells from individual triplicate flasks were harvested on day 6 to determine the REIC/Dkk-3 type-a expression using RT-PCR.

ER, PgR, and HER2 status in primary breast cancers

Estrogen receptor (ER), progesterone receptor (PgR), and HER2 status in primary breast cancers were obtained from patient medical records. HER 2 positive was defined as a score of $2+$ and $3+$ by immunohistochemistry.

\section{Statistical analyses}

The frequencies of REIC/Dkk-3 methylation between two groups were compared using the Fisher's exact test or Mann-Whitney's $U$ test when appropriate. Probability value less than 0.05 was defined as being statistically significant. All data were analyzed by JMP9 for Windows (SAS Institute, Cary, NC).

\section{Results}

DNA methylation status in the promoter region of $R E I C / D k k-3$ type-a

The results of bisulfite genomic DNA sequencing of RRCOBRA are shown in Fig. 1. Each CpG in the 5'-flanking region and in exon1a was heavily methylated in MCF7, MDA-MB-231, and ZR75-1. The CpGs in the 5'-flanking region of exon1a were lightly to moderately methylated, but the CpGs in exon1a were rarely methylated in HCC1806 and HCC1599. In contrast, most of the CpGs were rarely methylated in H1299.

We performed the linear regression analysis using the nested qCOBRA and confirmed the quantitative capacity (data not shown). Representative examples of the COBRA assay in breast cancer cell lines are shown in Fig. 2a. The percentages of REIC/Dkk-3 type-a methylation were calculated by qCOBRA in each cell line and primary tumor (Fig. 2b, c, respectively) and summarized in Table 1. We decided the samples with more than $10 \%$ of digested bands as methylation positive in this study. Aberrant methylation was detected in 7 of the $7(100 \%)$ breast cancer cell lines, 16 of the $37(43.2 \%)$ primary breast cancers, 5 of the 11 (45.4\%) lung cancer cell lines, 11 of the $42(26.2 \%)$ primary lung cancers, 0 of $4(0 \%)$ MPM cell lines, 7 of the 27 (25.9\%) USA primary MPMs, 7 of the 18 (38.9\%) Japanese primary MPMs, 8 of the $21(38.1 \%)$ primary gastric cancers, and 10 of the $20(50.0 \%)$ primary colon cancers. REIC/Dkk-3 methylation was not detected in 10 normal breast tissues and 10 normal lung tissues (data not shown). The methylation of REIC/Dkk-3 type-a in the breast cancer cell lines was more frequent than that in the lung, MPM, and prostate cancer cell lines $(p=0.02, p=0.01$, and $p=0.04$, respectively). However, no significant differences in methylation were observed among the primary breast, lung, MPMs, gastric, and colon cancers (Fig. 2c). The results of qCOBRA in five breast cancer cell lines and a lung cancer cell line (H1299) corresponded with the results of bisulfite sequencing.

REIC/Dkk-3 mRNA expression in cell lines and correlation with qCOBRA assay

Representative example of RT-PCR for REIC/Dkk-3 type-a and type-b in the breast cancer cell lines was shown in Fig. 2d. Expression of REIC/Dkk-3 type-a was only detected in HCC1599 and HCC1806 cells, which rarely to moderately harbored $R E I C / D k k-3$ methylation. Expression of REIC/Dkk-3 type-b was also detected in HCC1599 and HCC1806 cells. The results of expression of REIC/Dkk-3 type-a and type-b in all cell lines $(n=28)$ were summarized in Table 2. There was a correlation between the expression of $R E I C / D k k-3$ type-a and type-b $(p<0.01)$. The relative expressions of REIC/Dkk-3 type-a mRNA and the percentages of REIC/Dkk-3 type-a methylation are shown in Fig. 3. The expression of REIC/Dkk-3 type-a and REIC/Dkk-3 type-a methylation was inversely correlated in the cell lines that were examined $(p<0.01)$. To confirm that methylation was responsible for the gene silencing, heavily methylated MDA-MB-231 cells were treated with 5-Aza-CdR. REIC/ $D k k-3$ type-a mRNA expression was restored by the treatment of 5-Aza-CdR in a dose-dependent manner (Fig. 4).

REIC/Dkk-3 methylation and clinicopathological correlation

We next examined the relationships between the REIC/ $D k k-3$ methylation status and the clinicopathological 


\section{a}

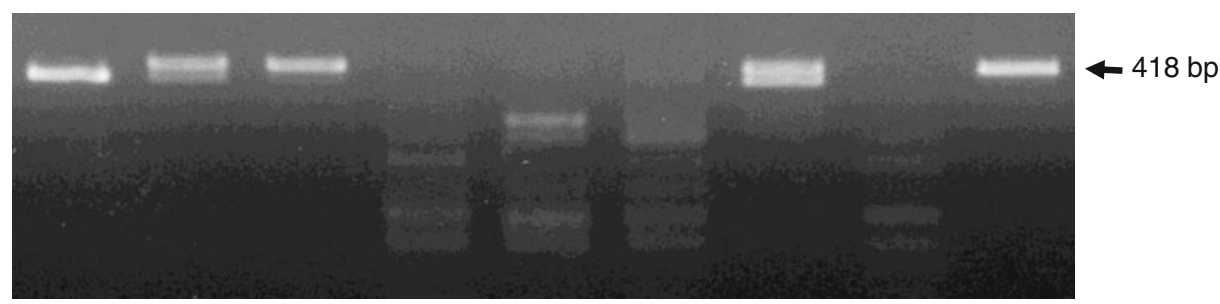

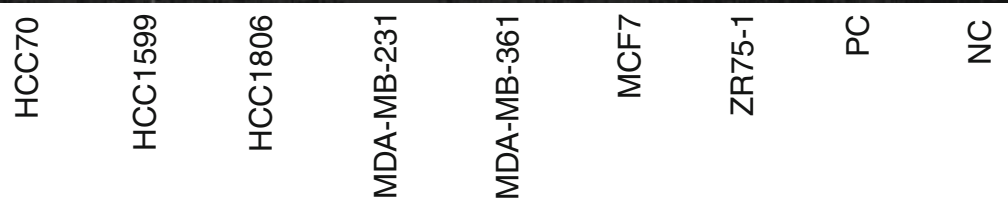
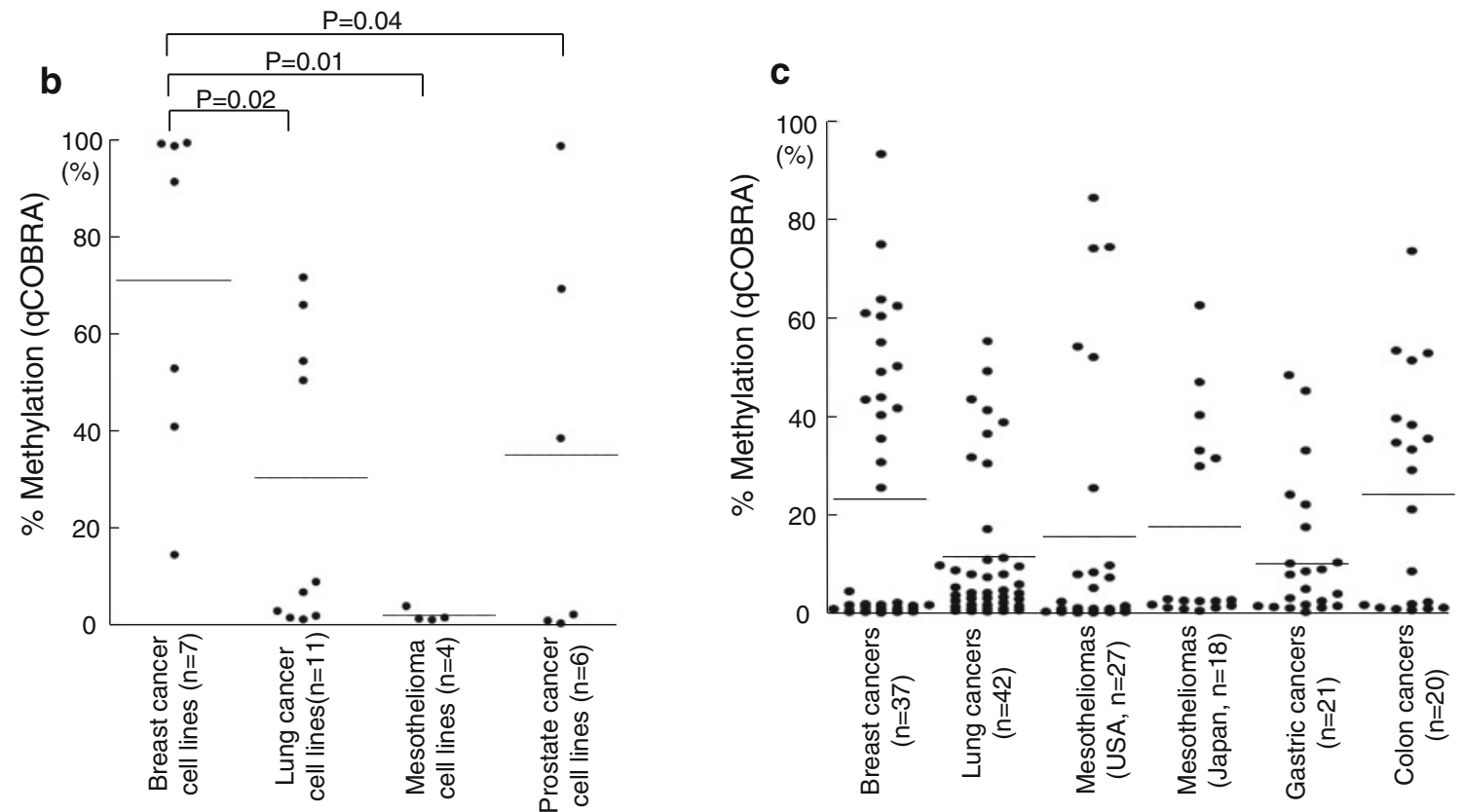

d

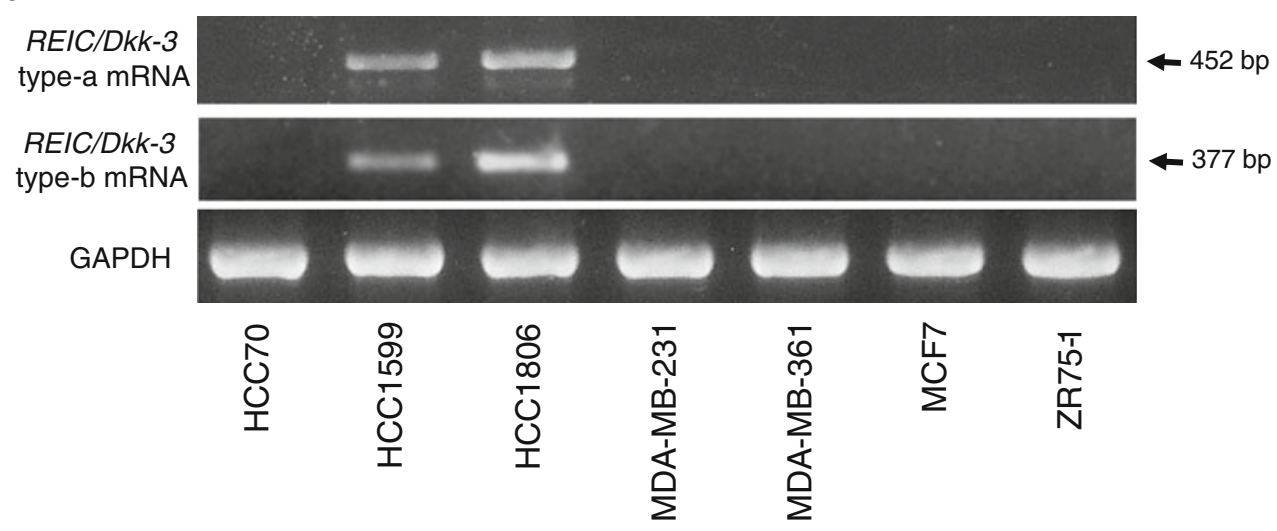

Fig. 2 Quantitative COBRA assay. The results of COBRA assay for REIC/Dkk-3 type-a in breast cancer cell lines were shown in

Image J $1.37 \mathrm{~V}$ software. The horizontal bars indicate the average in each group. The mRNA expression of REIC/Dkk-3 type-a and type-b in breast cancer cell lines was shown in d. $P C$ universal methylated a. Methylated alleles were fragmented with restriction enzyme modifiDNA as positive control; $N C$ universal unmethylated DNA as negative cation, and unmethylated alleles were uncut. Percentages of digested band in cell lines (b) and primary tumors (c) were quantitated by NIH control 
Table 1 Rate of REIC/Dkk3 methylation in each human cancer by quantitative COBRA assay

\begin{tabular}{lll}
\hline Organ & \multicolumn{2}{l}{ Number of $R E I C / D k k 3$} \\
\cline { 2 - 3 } & Cell lines & Primary tumors \\
\hline Breast cancer & 7 of $7(100 \%)$ & 16 of $37(43.2 \%)$ \\
Lung cancer & 5 of $11(45.4 \%)$ & 11 of $42(26.2 \%)$ \\
Malignant pleural mesothelioma & \\
USA & 0 of $4(0 \%)$ & 7 of $27(25.9 \%)$ \\
Japanese & ND & 7 of $18(38.9 \%)$ \\
Gastric cancer & ND & 8 of $21(38.1 \%)$ \\
Colon cancer & ND & 10 of $20(50.0 \%)$ \\
Prostate cancer & 3 of $6(50 \%)$ & ND \\
\hline
\end{tabular}

ND not determined

factors described in Table 3. For the breast cancers, we observed that ER-positive cases were more common in the methylated group than in the non-methylated group ( $p=0.03$ ). No significant relationships between REIC/Dkk3 methylation and the other clinicopathological factors were observed.

\section{Discussion}

In this study, we demonstrated that arbitrary CpG methylation in REIC/Dkk-3 type-a promoter region was frequently observed in solid malignancies. Regarding qCOBRA in this study, we confirmed the accuracy of this assay by linear regression analysis because we performed nested PCR. We decided the samples with more than $10 \%$ of digested bands as methylation positive to maintain compatibility with conventional COBRA assay, as we could distinguish $10 \%$ of digested band on the agarose gel electrophoresis. Colella et al. (2003) also used a 10\% threshold to declare methylation when qCOBRA was compared with pyrosequencing methylation analysis. So a $10 \%$ threshold seems to be reasonable criteria to distinguish methylation positive. We examined cell lines using qCOBRA assay, and the accuracy of the qCOBRA was also confirmed by bisulfate genomic DNA sequencing and linear regression analysis.

The REIC/Dkk-3 type-a methylation, which was determined using qCOBRA assay, revealed to be inversely correlated with the REIC/Dkk-3 type-a mRNA expression among the cell lines $(p<0.01)$, and the restoration of REIC/ $D k k-3$ type-a expression by 5 -Aza-CdR treatment was observed in a REIC/Dkk-3 type-a methylated cell line. These results indicate that DNA methylation of REIC/Dkk3 type-a was responsible for silencing REIC/Dkk-3 type-a expression. As reported previously, we confirmed that there was a correlation between REIC/Dkk-3 type-a expression
Table 2 Expression of $R E I C / D k k-3$ type-a and type-b in various cancer cells

\begin{tabular}{|c|c|c|}
\hline \multirow[t]{2}{*}{ Organ } & \multicolumn{2}{|c|}{ mRNA expression } \\
\hline & Type-a & Type-b \\
\hline \multicolumn{3}{|l|}{ Breast cancers } \\
\hline $\mathrm{HCC} 70$ & - & - \\
\hline HCC1599 & + & + \\
\hline HCC1806 & + & + \\
\hline MDA-MB-231 & - & - \\
\hline MDA-MB-361 & - & - \\
\hline MCF7 & - & - \\
\hline ZR75-1 & - & - \\
\hline \multicolumn{3}{|l|}{ Lung cancers } \\
\hline $\mathrm{H} 23$ & + & - \\
\hline H44 & - & - \\
\hline H125 & + & - \\
\hline H157 & + & + \\
\hline H1299 & + & + \\
\hline H1819 & + & + \\
\hline H1963 & + & + \\
\hline H1975 & - & + \\
\hline H2009 & - & - \\
\hline H358 & - & - \\
\hline A549 & + & + \\
\hline \multicolumn{3}{|l|}{$M P M s$} \\
\hline H 2052 & + & + \\
\hline $\mathrm{H} 2373$ & + & + \\
\hline $\mathrm{H} 2452$ & - & - \\
\hline $\mathrm{H} 290$ & + & + \\
\hline \multicolumn{3}{|c|}{ Prostate cancers } \\
\hline Caki-1 & + & + \\
\hline Caki-2 & + & + \\
\hline Du145 & + & + \\
\hline KPK & + & + \\
\hline LNCap-FGC & - & - \\
\hline PC3 & - & - \\
\hline
\end{tabular}

and type-b expression in the cell lines that we examined $(p<0.01)$. Discrepancy of the expression level between $R E I C / D k k-3$ type-a and type-b was observed in lung cancer cell lines, although the expression of REIC/Dkk-3 type-a completely corresponded with the expression of REIC/Dkk3 type-b in other cell lines, indicating that REIC/Dkk-3 type-b might be utilized for the expression in a tissue-specific manner, as Kobayashi et al. (2002) described.

Among the cancers that were examined, REIC/Dkk-3 type-a methylation was more frequently detected in breast cancer cell lines, although moderate methylation was also observed in other cancers. A previous report showed that the introduction of REIC/Dkk-3 into some breast cancer 


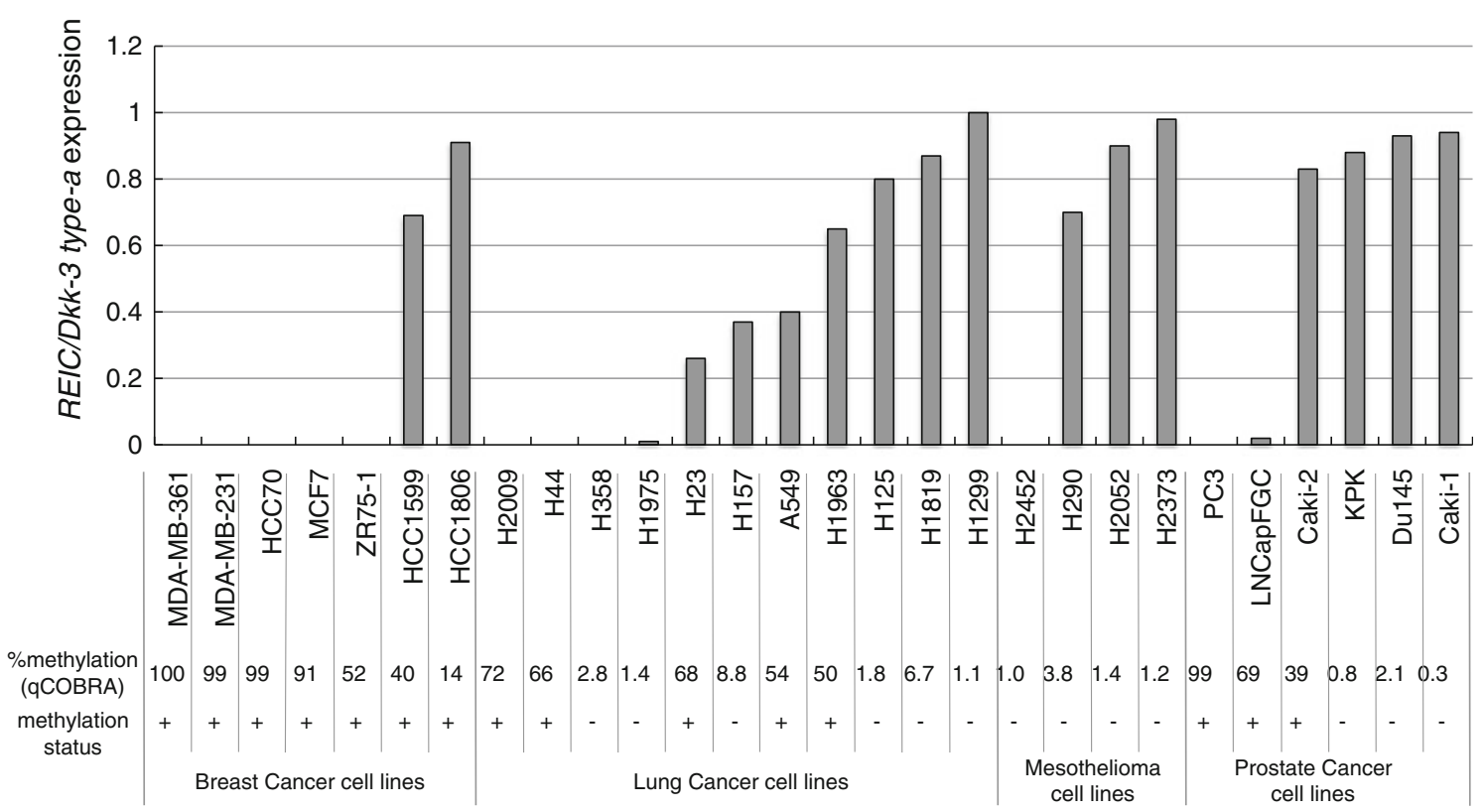

Fig. 3 Relative expression of REIC/Dkk-3 type-a mRNA and percentages of REIC/Dkk-3 methylation in each cell line. Columns show the relative expression of $R E I C / D k k-3$ type-a mRNA in each sample.

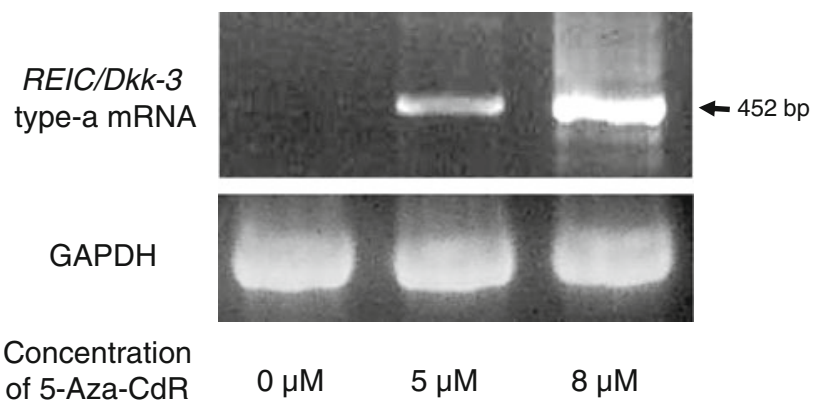

Fig. 4 Restoration of REIC/Dkk-3 type-a mRNA expression in MDAMB-231 cells. The effect of 5-Aza-CdR on the restoration of REIC/ $D k k-3$ type-a mRNA expressions in heavily methylated breast cancer cells (MDA-MB-231). REIC/Dkk-3 type-a mRNA was detected by RT-PCR. GAPDH was used as an internal control

cells had an antitumor effect (Kawasaki et al. 2009). In addition, the introduction of REIC/Dkk-3 into cancer cells had a direct effect on the induction of apoptosis and an indirect effect on the activation of tumor immunity in NK cells through the up-regulation of IL-7 (Sakaguchi et al. 2009). Furthermore, REIC/Dkk-3 induces the differentiation of human CD14+ monocytes into a novel cell type, resembling immature dendritic cells generated with IL-4 and GM-CSF (Watanabe et al. 2009). These findings support the possible utility of REIC/Dkk-3 gene therapy for not only breast cancers but also a broad range of human malignancies. Indeed, $R E I C / D k k-3$ gene therapy is ongoing for prostate cancer (http://clinicaltrials.gov/ct2/show/NCT01197209).

Regarding the clinicopathological factors, we found that ER-positive breast cancer was more common in the
The expression ratio was defined as the ratio of particular sample when compared to those of H1299. \% methylation was calculated by qCOBRA assay

methylated group than in the non-methylated group in the present study. In contrast, Veeck et al. (2009) reported that there was no correlation between REIC/Dkk-3 methylation and ER and PgR statuses. In other cancers, no significant relationship was observed between the REIC/Dkk-3 methylation status and any of the clinicopathological factors that were examined. Previous study has shown that REIC/Dkk-3 methylation was associated with poor survival in primary breast cancers (Veeck et al. 2009). We could not compare these results directly because they examined the REIC/Dkk-3 type-b methylation, which has a lower promoter activity than that of REIC/Dkk-3 type-a. In addition, the number of cases in this study may have been too small for the survival analysis, since the primary purpose of this study was to detect REIC/Dkk-3 type-a methylation and to examine the correlation between methylation and expression. In lung cancer, reduced expression of REIC/Dkk-3 was previously shown to be frequent in poorly differentiated adenocarcinoma and squamous cell carcinoma (Nozaki et al. 2001). Further investigations are needed to determine the clinicopathological impact of REIC/Dkk-3 type-a methylation.

In conclusion, we found that the promoter region of REIC/ $D k k-3$ type-a was frequently methylated in breast, lung, gastric, colon, and prostate cancers and MPMs. REIC/Dkk-3 type-a methylation and REIC/Dkk-3 type-a mRNA expression were inversely correlated in the cell lines that were examined. Our results suggest that REIC/Dkk-3 type-a methylation is an important mechanism in the pathogenesis of various types of malignancies. Since gene therapy using 
Table 3 Clinicopathological factors and REIC/Dkk-3 methylation in various primary cancers

\begin{tabular}{ll}
\hline Variables & $\begin{array}{l}\text { Number of } \\
\text { methylation-positive } \\
\text { samples }(\%)\end{array}$ \\
Total $(n=38)$ & $16(39)$ \\
\hline
\end{tabular}

\section{A. Primary breast cancers}

Age

$$
\begin{aligned}
& <65(n=32) \\
& \geq 65(n=6)
\end{aligned}
$$

$1(17)$

Histology

$$
\text { Papillotubular }(n=8)
$$

Solid-tubular $(n=11)$

Scirrhous $(n=17)$

Others $(n=2)$

0

$\mathrm{T}$ categories

$$
\begin{aligned}
& 1(n=11) \\
& 2(n=16) \\
& 3(n=3) \\
& 4(n=8)
\end{aligned}
$$

$\mathrm{N}$ categories

$$
\begin{aligned}
& 0(n=15) \\
& 1(n=23)
\end{aligned}
$$

M categories

$$
\begin{aligned}
& 0(n=36) \\
& 1(n=2)
\end{aligned}
$$

Stage

$$
\begin{aligned}
& \text { I }(n=9) \\
& \text { II }(n=15) \\
& \text { III }(n=12) \\
& \text { IV }(n=2)
\end{aligned}
$$

Estrogen receptor*

$$
\text { Positive }(n=19)
$$

Negative $(n=18)$

Progesterone receptor

$$
\text { Positive }(n=18)
$$

Negative $(n=15)$

HER2 status

$\begin{array}{ll}\text { Positive }(n=11) & 3(27) \\ \text { Negative }(n=19) & 10(53)\end{array}$

\begin{tabular}{ll}
\hline $\operatorname{Total}(n=41)$ & $11(27)$
\end{tabular}

B. Primary lung cancers

Age

$$
<65(n=17)
$$$$
\geq 65(n=24)
$$

Histology

Adenocarcinoma $(n=27)$

Squamous cell carcinoma $(n=14)$
Table 3 continued

\begin{tabular}{ll}
\hline Total $(n=41)$ & $11(27)$ \\
\hline T categories & $7(26)$ \\
$1(n=27)$ & $4(33)$ \\
$2(n=12)$ & 0 \\
$3(n=0)$ & 0 \\
$4(n=2)$ & \\
N categories & $8(28)$ \\
$0(n=29)$ & $2(20)$ \\
$1(n=10)$ & \\
M categories & $11(28)$ \\
$0(n=39)$ & 0 \\
$1(n=2)$ & \\
Stage & $8(29)$ \\
I $(n=28)$ & $1(25)$ \\
II $(n=4)$ & $1(14)$ \\
III $(n=7)$ & 0 \\
IV $(n=2)$ & $8(38)$ \\
\hline Total $(n=21)$ & \\
\hline
\end{tabular}

C. Primary gastric cancers

Age

$<65(n=10)$

$65 \leq(n=11)$

Histology

Intestinal $(n=10)$

Diffuse $(n=11) \quad 3$ (27)

$\mathrm{T}$ categories

$$
1(n=3)
$$

$2(n=8)$

$3(n=7)$

$4(n=3)$

0

$\mathrm{N}$ categories

$$
\begin{aligned}
& 0(n=7) \\
& 1 \leq(n=14)
\end{aligned}
$$

Stage

\begin{tabular}{l} 
I $(n=6)$ \\
II $(n=3)$ \\
III $(n=5)$ \\
IV $(n=7)$ \\
Total $(n=20)$ \\
\hline D. Primary colon cancers \\
Age \\
$<65(n=9)$ \\
$65 \leq(n=11)$
\end{tabular}
$10(50)$ 
Table 3 continued

\begin{tabular}{|c|c|}
\hline Total $(n=20)$ & $10(50)$ \\
\hline \multicolumn{2}{|l|}{ Histology } \\
\hline Well $(n=5)$ & $1(20)$ \\
\hline Moderately $(n=11)$ & $6(55)$ \\
\hline Poorly $(n=3)$ & $2(67)$ \\
\hline Others $(n=1)$ & $1(100)$ \\
\hline \multicolumn{2}{|l|}{$\mathrm{T}$ categories } \\
\hline $1(n=2)$ & $1(50)$ \\
\hline $2(n=0)$ & 0 \\
\hline $3(n=14)$ & $6(43)$ \\
\hline $4(n=3)$ & $3(100)$ \\
\hline \multicolumn{2}{|l|}{$\mathrm{N}$ categories } \\
\hline $0(n=8)$ & $4(50)$ \\
\hline $1 \leq(n=12)$ & $6(50)$ \\
\hline \multicolumn{2}{|l|}{ M categories } \\
\hline $0(n=12)$ & $6(50)$ \\
\hline $1(n=8)$ & $4(50)$ \\
\hline \multicolumn{2}{|l|}{ Stage } \\
\hline $\mathrm{I}(n=3)$ & $2(67)$ \\
\hline II $(n=4)$ & $1(25)$ \\
\hline III $(n=5)$ & $3(60)$ \\
\hline $\operatorname{IV}(n=8)$ & $4(50)$ \\
\hline \multicolumn{2}{|l|}{ Location } \\
\hline Right $(n=8)$ & $5(63)$ \\
\hline Left $(n=11)$ & $4(36)$ \\
\hline
\end{tabular}

$* p<0.05$

REIC/Dkk-3 expressing adenovirus vectors is currently ongoing for the treatment of prostate cancer, similar therapeutic modalities may be applicable for other types of cancers.

Acknowledgments We thank Professor Adi F. Gazdar, Hammon Center for Therapeutic Oncology Research, University of Texas Southwestern Medical Center at Dallas, TX, for kind gift of cell lines.

\section{Conflict of interest None.}

Open Access This article is distributed under the terms of the Creative Commons Attribution License which permits any use, distribution, and reproduction in any medium, provided the original author(s) and the source are credited.

\section{References}

Abarzua F, Sakaguchi M, Takaishi M, Nasu Y, Kurose K, Ebara S, Miyazaki M, Namba M, Kumon H, Huh NH (2005) Adenovirusmediated overexpression of REIC/Dkk-3 selectively induces apoptosis in human prostate cancer cells through activation of c-Jun-NH2-kinase. Cancer Res 65:9617-9622

Bafico A, Liu G, Yaniv A, Gazit A, Aaronson SA (2001) Novel mechanism of Wnt signalling inhibition mediated by Dickkopf-1 interaction with LRP6/Arrow. Nat Cell Biol 3:683-686
Colella S, Shen L, Baggerly KA, Issa JPJ, Krahe R (2003) Sensitive and quantitative universal Pyrosequencing methylation analysis of CpG site. Biotechniques 35:146-150

Edamura K, Nasu Y, Takaishi M, Kobayashi T, Abarzua F, Sakaguch M, Kashiwakura Y, Ebara S, Saika T, Watanabe M, Huh NH, Kumon H (2007) Adenovirus-mediated REIC/Dkk-3 gene transfer inhibits tumor growth and metastasis in an orthotopic prostate cancer model. Cancer Gene Ther 14:765-772

Glinka A, Wu W, Delius H, Monaghan AP, Blumenstock C, Niehrs C (1998) Dickkopf-1 is a member of a new family of secreted proteins and functions in head induction. Nature 391:357-362

Hoang BH, Kubo T, Healey JH, Yang R, Nathan SS, Kolb EA, Mazza BA, Meyers PA, Gorlick R (2004) Dickkopf 3 inhibits invasion and motility of Saos-2 osteosarcoma cells by modulating the Wntbeta-catenin pathway. Cancer Res 64:2734-2739

Hsieh SY, Hsieh PS, Chiu CT, Chen WY (2004) Dickkopf-3/REIC functions as a suppressor gene of tumor growth. Oncogene 23:9183-9189

Kashiwakura Y, Ochiai K, Watanabe M, Abarzua F, Sakaguchi M, Takaoka M, Tanimoto R, Nasu Y, Huh NH, Kumon H (2008) Down-regulation of inhibition of differentiation-1 via activation of activating transcription factor 3 and Smad regulates REIC/ Dickkopf-3-induced apoptosis. Cancer Res 68:8333-8341

Kawasaki K, Watanabe M, Sakaguchi M, Ogasawara Y, Ochiai K, Nasu Y, Doihara H, Kashiwakura Y, Huh NH, Kumon H, Date H (2009) REIC/Dkk-3 overexpression downregulates P-glycoprotein in multidrug-resistant MCF7/ADR cells and induces apoptosis in breast cancer. Cancer Gene Ther 16:65-72

Kobayashi K, Ouchida M, Tsuji T, Hanafusa H, Miyazaki M, Namba M, Shimizu N, Shimizu K (2002) Reduced expression of the REIC/Dkk-3 gene by promoter-hypermethylation in human tumor cells. Gene 282:151-158

Krupnik VE, Sharp JD, Jiang C, Robison K, Chickering TW, Amaravadi L, Brown DE, Guyot D, Mays G, Leiby K, Chang B, Duong T, Goodearl AD, Gearing DP, Sokol SY, McCarthy SA (1999) Functional and structural diversity of the human Dickkopf gene family. Gene 238:301-313

Kurose K, Sakaguchi M, Nasu Y, Ebara S, Kaku H, Kariyama R, Arao Y, Miyazaki M, Tsushima T, Namba M, Kumon H, Huh NH (2004) Decreased expression of REIC/Dkk-3 in human renal clear cell carcinoma. J Urol 171:1314-1318

Licchesi JD, Westra WH, Hooker CM, Machida EO, Baylin SB, Herman JG (2008) Epigenetic alteration of Wnt pathway antagonists in progressive glandular neoplasia of the lung. Carcinogenesis 29:895-904

Maehata $\mathrm{T}$, Taniguchi $\mathrm{H}$, Yamamoto $\mathrm{H}$, Nosho $\mathrm{K}$, Adachi $\mathrm{Y}$, Miyamoto N, Miyamoto C, Akutsu N, Yamaoka S, Itoh F (2008) Transcriptional silencing of Dickkopf gene family by $\mathrm{CpG}$ island hypermethylation in human gastrointestinal cancer. World $\mathrm{J}$ Gastroenterol 14:2702-2714

Nozaki I, Tsuji T, Iijima O, Ohmura T, Andou A, Miyazaki M, Shimizu N, Namba M (2001) Reduced expression of REIC/Dkk3 gene in non-small cell lung cancer. Int J Oncol 19:117-121

Roman-Gomez J, Jimenez-Velasco A, Agirre X, Castillejo JA, Navarro G, Barrios M, Andreu EJ, Prosper F, Heiniger A, Torres A (2004) Transcriptional silencing of the Dickkopfs-3 (Dkk-3) gene by $\mathrm{CpG}$ hypermethylation in acute lymphoblastic leukaemia. $\mathrm{Br} \mathrm{J}$ Cancer 91:707-713

Sakaguchi M, Kataoka K, Abarzua F, Tanimoto R, Watanabe M, Murata H, Than SS, Kurose K, Kashiwakura Y, Ochiai K, Nasu Y, Kumon H, Huh NH (2009) Overexpression of REIC/Dkk-3 in normal fibroblasts suppresses tumor growth via induction of interleukin-7. J Biol Chem 284:14236-14244

Toyooka S, Shimizu N (2004) Models for studying DNA methylation in human cancer: a review of current status. Drug Discov Today $1: 37-42$ 
Tsuji T, Miyazaki M, Sakaguchi M, Inoue Y, Namba M (2000) A REIC gene shows down-regulation in human immortalized cells and human tumor-derived cell lines. Biochem Biophys Res Commun 268:20-24

Tsuji T, Nozaki I, Miyazaki M, Sakaguchi M, Pu H, Hamazaki Y, Iijima I, Namba M (2001) Antiproliferative activity of REIC/ Dkk-3 and its significant down-regulation in non-small-cell lung carcinomas. Biochem Biophys Res Commun 289:257-263

Veeck J, Wild PJ, Fuchs T, Schüffler PJ, Hartmann A, Knüchel R, Dahl E (2009) Prognostic relevance of Wnt-inhibitory factor-1 (WIF1) and Dickkopf-3 (DKK3) promoter methylation in human breast cancer. BMC Cancer 9:217
Watanabe M, Kashiwakura Y, Huang P, Ochiai K, Futami J, Li SA, Takaoka M, Nasu Y, Sakaguchi M, Huh NH, Kumon H (2009) Immunological aspects of REIC/Dkk-3 in monocyte differentiation and tumor regression. Int J Oncol 34:657-663

Xiong Z, Laird PW (1997) COBRA: a sensitive and quantitative DNA methylation assay. Nucleic Acids Res 25:2532-2534

Yue W, Sun Q, Dacic S, Landreneau RJ, Siegfried JM, Yu J, Zhang L (2008) Downregulation of Dkk3 activates beta-catenin/TCF-4 signaling in lung cancer. Carcinogenesis 29:84-92 